\title{
The Relationship Among Couple Relationship Quality, Physical Functioning, and Depression in Multiple Sclerosis Patients and Partners
}

Justin K. McPheters

LDS Family Services

Jonathan G. Sandberg

Brigham Young University - Provo, jonathan_sandberg@byu.edu

Follow this and additional works at: https://scholarsarchive.byu.edu/facpub

Part of the Other Social and Behavioral Sciences Commons

\section{Original Publication Citation}

McPheters, J.K., \& Sandberg, J.G. (2010). The relationship among couple relationship quality, physical functioning, and depression in multiple sclerosis patients and partners. Families, Systems, and Health, 28(1), 48-68.

\section{BYU ScholarsArchive Citation}

McPheters, Justin K. and Sandberg, Jonathan G., "The Relationship Among Couple Relationship Quality, Physical Functioning, and Depression in Multiple Sclerosis Patients and Partners" (2010). Faculty Publications. 4068.

https://scholarsarchive.byu.edu/facpub/4068 


\section{The Relationship Among Couple Relationship Quality, Physical Functioning, and Depression in Multiple Sclerosis Patients and Partners}

Justin K. McPheters, PhD

Jonathan G. Sandberg, PhD

Using Engel's biopsychosocial model and family systems theory, this study explored the associations between multiple sclerosis (MS) patient and partner reports of physical functioning, depression, and couple relationship quality. Fifty-four couples recruited from the MS society completed self-report questionnaires about couple relationship quality, demographic data, and physical functioning. In regression analyses, couple relationship quality positively related to $M S$ patient physical functioning and depression negatively related to $M S p a-$ tient physical functioning. Both MS patient and partner reports of couple relationship quality negatively related to depression scores in partners. While MS patient reports of couple relationship quality negatively related to $M S$ patient depressions scores, partner reports of couple relationship quality were not significantly related. Depression and couple relationship quality were associated with MS patient physical functioning. Couples with higher relationship quality may be better able to cope with

Justin K. McPheters, PhD, LDS Family Services, Chicago, IL; Jonathan G. Sandberg, PhD, Marriage and Family Therapy Program, School of Family Life, Brigham Young University.

Correspondence concerning this article should be addressed to Jonathan G. Sandberg, 266 TLRB, Brigham Young University, Provo, UT 84602. E-mail: jonathan_sandberg@byu.edu the stresses of MS. Thus, clinicians and health care providers need to include partners in MS patient treatment. Further research is needed to better explain causality between MS patient physical functioning, depression, and couple relationship quality.

Keywords: couple relationship quality, multiple sclerosis, depression

A pproximately 400,000 people in the United States have been diagnosed with multiple sclerosis (MS), with an estimated 2.5 million people living with MS worldwide (National Multiple Sclerosis Society [NMSS], 2006). MS is a degenerative disease of the central nervous system characterized by unpredictable exacerbation and remission of symptoms such as fatigue, cognitive impairment, difficulty walking and balancing, sexual dysfunction, and vision problems (NMSS, 2006). With such devastating symptoms, MS has a major impact on the biopsychosocial well being of individuals, couples, families, and larger systems.

\section{THE CONTEXT FOR THE PROBLEM: FAMILY SYSTEMS THEORY AND THE BIOPSYCHOSOCIAL MODEL}

Family systems theory serves as a theoretical base for the present research (Broderick, 1995). Specific to illness, family systems theory focuses on the system created 
by the interaction of physical illness with an individual, couple, family, and other biopsychosocial systems (Rolland, 1994). When an individual within a family system is diagnosed with an illness, family roles and rules may need to be adjusted. The homeostatic nature of the family system is challenged, and family members may struggle to adapt to the changes. All family members participate in the new system created by the introduction of the illness, and members are often required to renegotiate roles within this new system.

Another systemic model that elucidates the interconnection of individuals, couples, and families with illness is the biopsychosocial model of health and illness (Engel, 1977, 1980), which marked a dramatic shift from disease to health. In contrast to the biomedical model of medicine, the biopsychosocial model takes into account the patient, social context, and health care system rather than focusing solely on biology and pathology. Within this model, boundaries between health and illness become blurred by cultural, social, and psychological considerations (Engel, 1977). Like family systems theory, the biopsychosocial model considers health and illness as inseparably connected to the various systems in which an individual resides. The biopsychosocial model also recognizes that important components of health include a good quality of life and strong relationships (Engel, 1977).

\section{COUPLES, HEALTH, AND CHRONIC ILLNESS}

The systemic and biopsychosocial idea that health and relationships are connected is heavily supported in research literature examining couples, health, and illness (e.g., Wickrama, Lorenz, \& Conger, 1997). The influence of social relationships on health has been shown to parallel medical risk factors such as smoking, blood pressure, obesity, and physical activity (Campbell, 2003; House, Landis, \& Umberson, 1988). Chronic illness can also be a relationally traumatizing experience affecting members of the family as well as the individual diagnosed with the illness (Penn, 2001). While many social relationships impact and are impacted by health and illness, the couple relationship plays a particularly poignant role as it is the most central relationship for the majority of adults (Kiecolt-Glaser \& Newton, 2001).

It is the quality of the couple relationship that seems to play a key role in understanding health and illness. In a review of 64 articles, most based on marital interaction studies, researchers concluded that health is impacted by marital functioning (Kiecolt-Glaser \& Newton, 2001), wherein the presence of a chronic illness may decrease, increase, or be unrelated to the level of marital satisfaction in a couple (Burman \& Margolin, 1992; Schmaling \& Sher, 2000). Burman and Margolin (1992) explained the varied findings regarding couples, health, and illness in terms of the social strain-social support hypothesis, which takes into account the level of support within the couple relationship. The following review considers two key areas of couple functioning that play a part in health and illness and are central to the current study of couples with MS.

\section{Relationship Quality}

Proulx, Helms, and Buehler (2007) examined the association between marital quality and personal well-being by conducting a meta-analysis of 93 studies. Researchers in both cross-sectional and longitudinal studies found higher levels of marital quality to be associated with significantly higher levels of personal wellbeing, with said association persisting over time (Proulx et al., 2007). In addition, marital quality was shown to be related to survival rates after congestive heart failure and kidney disease (Coyne et al., 2001; Kimmel et al., 2000), and higher marital quality was related to lower biopsychosocial risk factors for cardiovascular disease (Gallo, Troxel, Matthews, \& Kuller, 2003). 
Overall, men and women who report better marital quality also report better health, fewer illness symptoms, and better sleep patterns (Gallo et al., 2003; Prigerson, Maciejewski, \& Rosenheck, 1999; Ross, Mirowsky, \& Goldsteen, 1990; Thomas, 1995). Low marital quality has been shown to be detrimental to physical health and well-being, as well as related to depression, reduced immune system functioning, and even dental problems (Greene \& Griffin, 1998; Keicolt-Glaser et al., 1987, 1988, 1993, 1997, 2001, 2005; Marcenes \& Sheiham, 1996).

In summary, meta-analyses of marriage and health studies concluded that negative dimensions of marital functioning affect health indirectly through depression and health habits and directly through cardiovascular, immune, neurosensory, endocrine, and other physiological mechanisms (Kiecolt-Glaser \& Newton, 2001). In fact, low marital quality may do more damage to health than high marriage quality benefits health (Coyne \& Bolger, 1990). KiecoltGlaser and Newton (2001) concluded that negative aspects of couple relationships were independent from positive aspects, which suggests a need to specifically consider negative and positive aspects of the couple relationship in the current review.

\section{Depression}

Among the multifaceted factors related to the etiology of depression across gender, culture, and age groups, research has shown that depression is associated with marital discord (Bookwala \& Franks, 2005; Finchman \& Beach, 1999; Hollist, Miller, Falceto, \& Fernandes, 2007; O'Leary, Christian, \& Mendell, 1994; Sandberg \& Harper, 2000). The interaction between depression and couple relationships appears to be systemic in nature, with struggling couple relationships increasing depression and higher levels of depression leading to lower couple relationship satisfaction. Depression has also been shown to alter cardiovascular, immune, and endocrine func- tioning (Glassman \& Shapiro, 1998; Kiecolt-Glaser \& Newton, 2001; Simonsick, Wallace, Blazer, \& Berkman, 1995). These findings suggest that depression impacts and is impacted by various biological, psychological, and social influences.

\section{Physical/Physiological Functioning}

High marital functioning has been shown to improve physical functioning, including survival rates after heart failure (Coyne et al., 2001) and kidney disease (Kimmell et al., 2000), and to enhance cardiovascular, endocrine, and immune system functioning (Kiecolt-Glaser, 2001; Uchino, Cacciopo, \& Kiecolt-Glasser, 1996). Research has also shown that wound healing and cytokine production was lower at wound sites and wounds healed more slowly after marital conflicts than during supportive marital interactions (Kiecolt-Glaser et al., 2005). In a study of marital closeness and functional disability later life, researchers found that marital closeness mediated the negative relationship between physical disability and depression and anxiety (Mancini \& Bonanno, 2006). Yorgason, Almeida, Neupert, Spiro, and Hoffman (2006) report that higher negative mood and lower positive mood were reported in couples where the partner had higher symptoms. Although less developed than the bodies of research related to the other key factors previously reviewed, there is sufficient evidence to highlight the link between marital functioning and physiological functioning in marriage.

\section{THE BIOPSYCHOSOCIAL ASPECTS OF MS FOR COUPLES \\ Activities of Daily Living}

MS symptoms can make it difficult to engage in activities of daily living (e.g., self care, mobility, and house hold tasks) (Aronson, 1997; Zeldow \& Pavlou, 1994). Researchers have estimated, among many difficult symptoms, that half of those diag- 
nosed with MS will not be able to work within 10 years of diagnosis, struggle to walk after 15 years, and be unable to walk after 25 years (Einarsson, Gottberg, Fredrikson, von Koch, \& Holmqvist, 2006; Gottberg, Einarsson, Fredrikson, von Koch, \& Holmqvist, 2007; Noseworthy, Lucchinetti, Rodriguez, \& Weinshenker, 2000; Walker \& Gonzalez, 2007; Weinshenker, 1994).

Gulick (2001) examined responses of 686 persons with MS who filled out self-report measures and concluded that emotional distress also significantly affected activities of daily living (ADL) functioning. Specifically, personal attributes (sense of humor, positive attitude, faith and hope, and control of stress) and social support (assistance with tasks, emotional support, and financial support) were shown to be mediators in this relationship by limiting the impact that emotional distress had on ADL.

\section{Depression and MS}

Depression, depressive symptoms, and major depressive disorder are more common among people with MS than the general population and individuals with other disabling chronic illness (Ghaffar \& Feinstein, 2007; NMSS, 2006). Depression was reported to be the greatest predictor of quality of life for persons with MS and a strong predictor of physical functioning for persons with MS (D'Alisa et al., 2006). Research has shown that disease-specific factors (symptom exacerbation, illness uncertainty) have been related to higher levels of depression (Kroencke, Denney, \& Lynch, 2001). However, it should also be noted that research has highlighted depressive symptoms vary over time for many MS patients (Arnett \& Randolph, 2006). In addition, the variability of MS symptom severity for relapse-remitting patients (see NMSS, 2006) seems to be related to changes in depressive symptoms as well (Randolph \& Arnett, 2005).

The "Goldman Consensus Statement on depression in multiple sclerosis" (Goldman consensus group, 2005), summarized findings from epidemiologic, neurobiologic, and therapeutic studies related to depressive disorders among MS patients. In this landmark report, the group concluded that "the etiology of depressive spectrum disorders in MS is not completely understood, but it thought to be multifactorial, with psychological, social, and neurobiological factors all playing a role-and potentially immunologic and genetic factors as well" (p. 332). Therefore, despite emerging research it is still unclear how depression and martial functioning are related in the lives of MS patients and partners and how that interaction influences MS symptoms.

\section{Marital Functioning and MS}

The current literature review on the social impact of MS yielded a number of studies that examined marital functioning in MS patient/partner pairs (King \& Arnett, 2005; Kleiboer, Kuijer, Hox, Jongen, Frequin, \& Bensing, 2007; Kleiboer, Kuijer, Hox, Schreuurs, \& Bensing, 2006; Van der Linden et al., 2006; Wineman, O'Brien, Nealon, \& Kaskel, 1993; Woollett \& Edelmann, 1988). Among these studies, only one considered biological, psychological, and social (specifically marital factors) aspects of MS patient and partner functioning in couple pairs. The researchers collected data from 18 couples, and by looking at correlational links, were able to show trend level significance between couple relationship quality and ADL functioning in MS patients. In a related study of MS patient perceptions of spousal responses to disability, Schwartz and Kraft (1999) reported that solicitous spousal responses were significantly related to greater MS specific physical disability, particularly when patients were more depressed. Negative spouse responses were correlated with poorer mental health for patients. These two studies provide initial support for associations among biological, psychological, and marital variables related to MS in couple pairs, although each has signifi- 
cant design, sample, and/or analytic limitations. Clearly additional research is needed in this area.

\section{PURPOSE OF THE PRESENT STUDY}

The literature regarding couple relationships and health has demonstrated a clear link between couple relationship quality and physical functioning. The MS literature shows a complex interconnection between biological, psychological, and social factors impacting persons living with MS, though extremely limited attention has been paid to couple relationship quality and its relation to the psychological and physical functioning of MS patients and their partners. Therefore, research is needed to examine the link between couple relationship quality, psychological functioning, and physical functioning to fill this hole in the existing MS literature. The proposed analysis will address three hypotheses regarding the relationships among couple relationship quality, depression, and physical functioning for MS patients and their partners.

Hypothesis 1: Partner and patient reports of couple relationship quality will be positively related to and significant predictors of MS patient physical functioning.

Hypothesis 2: Patient and partner depression scores will be positively related to and significant predictors of MS patient physical functioning.

Hypothesis 3: Partner and patient reports of couple relationship quality scores will be negatively related to and significant predictors of patient and partner depression, after controlling for MS patient physical functioning.

\section{METHODOLOGY}

\section{Procedure}

Participants were recruited through the Greater Illinois Chapter of the NMSS and were sent a copy of the study packet (letter of consent, questionnaires, and self-addressed stamped envelopes). They were also notified that they would receive a $\$ 10$ gift certificate (one per couple) for returning a consent form and completed survey from both partners. The questionnaires were assigned an identification number upon distribution to ensure the confidentiality of all participants. The identification numbers also enabled the researcher to group and analyze returned responses according to partner sets. Responses were only included in the study if both the MS patient and partner returned the survey.

\section{Sample and Response Rate}

Of the 500 questionnaire packets sent, 21 were returned with return-to-sender notices. Current address information could not be located for those persons through an Internet search. Eleven questionnaire packets were returned with a note indicating that the MS patient was deceased. Using Dillman's formula (Dillman, 2000), which adjusts for undeliverable surveys such as the aforementioned bad addresses and deceased persons, the overall one-time mailing response rate was $18 \%$. This number is based on 82 responses from 468 potential respondents. Because of the stringent requirement of complete data from both the MS patient and partner, an additional 28 responses were excluded, including 20 responses from individuals indicating that the study did not apply to them because they did not currently have a partner (they were either never married, divorced, or widowed), they reported that there was nobody in the household with MS, but they were affiliated with the NMSS because of a family member with MS, or respondents reported that they never had any affiliation with the NMSS and were unsure why they were on the mailing list. In addition, seven couples were excluded because one of the partners failed to return the questionnaire. Lastly, one couple returned a completed survey for 
both partners, but it was not included in the analysis because both partners reported an MS diagnosis. This left 54 couples (54 MS patients and 54 partners) that had complete data for inclusion in the present study.

\section{Study Participants}

The MS patient sample was $80 \%$ female, 91\% White/European, and 26\% employed. MS patients reported a mean age of 53.17 years $(S D=10.28)$ and a mean age of diagnosis with $\mathrm{MS}$ at 34.74 years $(S D=$ 9.54), which makes the mean number of years living with MS $18.43(S D=10.58)$. Concerning the form of MS, $56 \%$ of the MS patient sample was diagnosed with relapsing-remitting $\mathrm{MS}, 22 \%$ with secondary-progressive MS, and $11 \%$ with progressive-relapsing and primary-progressive MS, respectively. MS medication was used by $82 \%$ of the patient sample, and $69 \%$ used some type of assistive device for ambulation.

The partner sample was $80 \%$ male, $93 \%$ White/European, and $76 \%$ employed. The mean age of the partner sample was 54.43 $(S D=10.10)$. Of the couples measured in this study, 57\% reported a family household income of less than $\$ 75,000,94 \%$ were married, $80 \%$ had children, and $32 \%$ had children at home. Couples reported the number of mean years with their current partner at $26.78(S D=12.42)$ with $80 \%$ partnering before an MS diagnosis.

\section{Measures}

In addition to demographic questions, participants were also asked to complete standardized measures for depression, couple relationship quality and physical functioning.

\section{Depression}

Levels of depression were measured using the Center for Epidemiological Studies Depression Scale (CES-D; Radloff, 1977), which is designed to measure frequency and intensity of depressive symptoms oc- curring during the previous week. Potential total scores ranged from $0-60$ with higher scores indicating higher levels of depressive symptoms. Respondents scoring higher than 16 on the CES-D may need clinical services to address depression (Myers \& Weissman, 1980; Roberts \& Vernon, 1983). The CES-D has previously been used in research involving adults with physical disabilities and MS (Coyle \& Roberge, 1992; Gold-Spink et al., 2000). The author of the CES-D reported a Cronbach's coefficient alpha of .85 in the general population and .90 in a patient sample (Radloff, 1977). In the present study, Cronbach's alpha reliability coefficient was .91 for the combined MS patient and partner sample, indicating an internally consistent measure.

\section{Couple Relationship Quality}

The Dyadic Adjustment Scale was used to measure couple relationship satisfaction (DAS; Spanier, 1976). The DAS is a wellvalidated, 32-item measure widely used in measuring couple relationship quality (Epstein \& Baucom, 1988). Scores were based on values assigned to each response as laid out in Spanier (1977), with possible scores ranging from $0-151$. High scores indicated high levels of perceived couple relationship. The DAS author reported a Cronbach's coefficient $\alpha$ of .96 and a mean score of 114.8 among married couples (Spanier, 1976). A common cutoff score for distinguishing between distressed and nondistressed couples is 107 (Crane, Allgood, Larson, \& Griffin, 1990). Cronbach's alpha reliability coefficient in this study was .96 for the combined MS patient and partner sample, indicating an internally consistent measure.

\section{Physical Functioning}

MS patient and partner physical functioning was measured with the Activities of Daily Living Self-care Scale for Persons with Multiple Sclerosis (ADL-MS; Gulick, 2003), which assesses the frequency with 
which MS patients were able to perform various activities of daily living. Responses were based on the level of functioning on a typical day. ADL-MS scores range from $0-75$, with higher scores indicating higher levels of ADL. The ADL-MS author reports Cronbach's alpha ranging from .89 to .96 (Gulick, 1987), and one study of 686 MS patients reported a mean score of 49.35 ( $S D=$ 15.9; Gulick, 2001). In this study, Cronbach's alpha was .91 for a 14-item version of the ADL-MS with a range of 0-70 used to assess MS patient and partner physical functioning. One item asking about participation in recreational activities outside the home was omitted from the scale because of researcher error in preparation and distribution of the survey. However, the scale included a similar question concerning participation in social activities outside the home.

\section{RESULTS}

\section{Descriptive Statistics}

MS patients reported a mean physical functioning score of $50.02(S D=16.50)$ on the ADL-MS, which had a potential range of 0-70 with higher scores indicative of higher physical functioning. For comparative purposes, the mean score of the partners of the MS patient $63.1(S D=17.18)$. The difference between MS patient and partner ADL-MS scores was significant, $t(52)=5.32, p<.001$, with MS patients exhibiting lower physical functioning than their partners.

MS patients reported a mean depression score of $16.41(S D=10.94)$ on the CES-D which had a potential range of $0-60$ with a cutoff score of 16 or higher indicating a potential need for clinical services for depression. Partners reported a mean CES-D score of $10.56(S D=9.58)$. The difference between MS patient and partner CES-D scores was significant, $t(52)=4.00, p<.001$, with MS patients demonstrating higher levels of depression than their partners.

MS patients reported a mean couple relationship quality score of 112.81 ( $S D=$ 22.24 ) on the DAS which had a potential range of 0-151 with a cutoff scores of 107 or lower indicating distressed couple functioning (Crane at al., 1990). Partners reported a mean DAS score of 110.20 ( $S D=$ 21.40). The difference between MS patient and partner DAS scores was not statistically significant, $t(52)=1.09, p=.28$. The correlation between MS patient and partner DAS scores was highly significant $(r=$ $.67, p<.001)$.

\section{Hypothesis Testing}

Each hypothesis was tested separately, using a form of regression analysis. The results are presented sequentially (step-bystep) to highlight the amount of variance explained by each variable as it is added to the model. Hypothesis 1 stated that partner and MS patient couple relationship quality would be positively related to and significant predictors of MS patient physical functioning. The relationship between MS patient and partner reports of couple relationship quality (as measured by the DAS) and MS patient physical functioning (as measured by the ADL-MS) was investigated using Pearson product-moment correlation coefficient. Preliminary analyses were performed to ensure no violation of the assumptions of normality, linearity and homoscedasticity.

There was a significant positive correlation between the two variables, $r=.33, p<$ .05 , with high levels of partner ratings of couple relationship quality associated with higher levels of MS patient physical functioning. MS patient couple relationship quality did not significantly correlate with MS patient physical functioning in this sample $(r=.23, p<.10)$. Deal and Anderson (1995) suggest that meaningfulness need not be replaced by statistical significance. Although the correlation between MS patient DAS and ADL-MS is not statis- 
tically significant $p<.05$, the trend level significance is still be meaningful and warrants inclusion in the following regression model.

Table 1 shows results from hierarchical multiple regressions used to test first two research hypotheses, namely the capacity of couple relationship quality (DAS) and depression (CES-D) to predict MS patient physical functioning (ADL-MS), after controlling for the influence of length of time in the couple relationship and the age of the MS patient. Table 1 displays the results step-by-step to highlight the amount of variance explained by each variable as it is added to the model. MS patient age and length of time in couple relationship were added to the regression model based on the significant correlations with MS patient physical functioning to reduce the error in predicting MS patient physical functioning (Norusis, 1993). Length of time in the couple relationship and age of MS patient were entered at Step 1, explaining 13\% of the variance in MS patient physical functioning. After entry of partner ratings of couple relationship quality at Step 2, the total variance explained by the model was $26 \%, F(3,50)=5.71, p<.01$. Partner reports of couple relationship quality explained an additional 13\% of the variance in MS patient physical functioning, $R^{2} \Delta=$ $13, F \Delta(1,50)=8.58, p<.01$. In the final model, partner ratings of couple relationship quality was the only statistically significant variable $(\beta=.36, p<.01)$.

In a comparable regression model (see also Table 1), length of time in the couple relationship and age of MS patient were entered at Step 1, explaining 13\% of the variance in MS patient physical functioning. Though not significantly associated in bivariate correlations, MS patient ratings of couple relationship quality were entered at Step 2. The total variance explained by the model was $20 \%, F(3,50)=$ $4.13, p<.05$. MS patient reports of couple relationship quality explained an additional $7 \%$ of the variance in MS patient physical functioning, $R^{2} \Delta=.07, F \Delta(1,50)=$ $4.46, p<.05$. In the final model, MS patient reports of couple relationship quality was the only statistically significant variable $(\beta=.27, p<.05)$.

Table 1

Multiple Regressions on MS Patient Physical Functioning (ADL-MS) Variable $\beta$

\begin{tabular}{|c|c|c|}
\hline Variable & $\beta$ & $R^{2}$ \\
\hline Age & -.28 & \\
\hline Years with partner & -.09 & $R^{2}=.13$ \\
\hline \multicolumn{3}{|l|}{ Adding partner DAS } \\
\hline Age & -.11 & \\
\hline Year with partner & -.30 & \\
\hline Partner DAS & $.36^{* *}$ & $R^{2}=.26, R^{2} \Delta=.13$ \\
\hline \multicolumn{3}{|l|}{ Adding MS patient DAS } \\
\hline Age & -.12 & \\
\hline Years with partner & -.28 & \\
\hline MS patient DAS & $.27^{*}$ & $R^{2}=.20, R^{2} \Delta=.07$ \\
\hline \multicolumn{3}{|c|}{ Adding MS patient CES-D } \\
\hline Age & -.11 & \\
\hline Years with partner & $-.33^{*}$ & \\
\hline MS patient CES-D & $-.58^{* * * *}$ & $R^{2}=.46, R^{2} \Delta=.33$ \\
\hline \multicolumn{3}{|l|}{ Adding partner CES-D } \\
\hline Age & -.11 & \\
\hline Years with partner & $-.43^{*}$ & \\
\hline Partner CES-D & $-.50^{* * * *}$ & $R^{2}=.35, R^{2} \Delta=.22$ \\
\hline
\end{tabular}


Hypothesis 2 stated that partner and MS patient depression scores would be negatively related to and significant predictors of MS patient physical functioning. The relationship between MS patient and partner depression scores (as measured by the CES-D) and MS patient physical functioning (as measured by the ADL-MS) was investigated using Pearson product-moment correlation coefficient. There was a significant negative correlation between MS patient physical functioning and MS patient depression scores $(r=-.53, p<.001)$, partner depression scores $(r=-.33, p<$ $.05)$, MS patient age $(r=-.31, p<.05)$, and years with current partner $(r=-.35$, $p<.01)$.

Table 1 also shows results from hierarchical multiple regressions used to assess the ability of MS patient and partner depression scores to predict MS patient physical functioning, after controlling for length of time in couple relationship and MS patient age. Again, MS patient age and length of time in couple relationship were added to the regression model based on the significant correlation coefficients to reduce the error in predicting MS patient physical functioning (Norusis, 1993). MS patient age and couple relationship time were entered at Step 1, explaining $13 \%$ of the variance in MS patient physical functioning. After entry of MS patient depression scores at Step 2, the total variance explained by the model was $46 \%, F(3,50)=$ 13.90, $p<.001$. MS patient depression scores explained an additional $33 \%$ of the variance in MS patient physical functioning, after controlling for length of couple relationship and MS patient age, $R^{2} \Delta=$ $.33, F \Delta(1,50)=30.02, p<.001$. In the final model, two of the variables were statistically significant, with MS patient depression scores recording a higher beta value $(\beta=-.58, p<.001)$ than length of couple relationship $(\beta=-.33, p<.05)$.

In a comparable hierarchical regression model (see also Table 1), MS patient age and couple relationship time were entered at Step 1, explaining $13 \%$ of the variance in MS patient physical functioning. After entry of partner depression scores at Step 2, the total variance explained by the model was $35 \%, F(3,50)=9.00, p<.001$. Partner depression scores explained an additional $22 \%$ of the variance in MS patient physical functioning, $R^{2} \Delta=.22, F \Delta(1,50)=17.22$, $p<.001$. In the final model, two of the variables were statistically significant, with partner depression scores recording a higher beta value $(\beta=-.50, p<.001)$ than length of couple relationship $(\beta=$ $-.43, p<.05)$.

Hypothesis 3 stated that partner and patient reports of couple relationship quality scores would be negatively related to and significant predictors of patient and partner depression after controlling for MS patient physical functioning. The relationship between MS patient and partner reports of depression (as measured by the CES-D) and MS patient physical functioning (as measured by the ADL-MS) was investigated using Pearson product-moment correlation coefficient. Preliminary analyses were performed to ensure no violation of the assumptions of normality, linearity, and homoscedasticity. There was a significant negative relationship between MS patient depression scores and MS patient reports of couple relationship quality $(r=$ $-.49, p<.01)$, partner reports of couple relationship quality $(r=-.34, p<.05)$, MS patient physical functioning $(r=-.53, p<$ $.01)$, and male gender $(r=-.29, p<.05)$. This means that higher levels of depression in MS patients correlated with lower levels of MS patient reports of couple relationship quality, partner reports of couple relationship quality, and MS patient physical functioning. Additionally, men reported lower levels of depression than women.

In addition, there was a significant negative relationships between partner depression scores and MS patient reports of couple relationship quality $(r=-.55, p<$ .01 ), partner reports of couple relationship quality $(r=-.70, p<.01)$, MS patient 
physical functioning $(r=-.33, p<.05)$, and length of couple relationship $(r=$ $-.33, p<.05)$. Length of couple relationship did not significantly correlate to MS patient depression scores $(r=-.10, p=$ .46), and gender did not significantly correlate to partner depression scores $(r=$ $-.24, p=.08$ ).

Table 2 shows results from hierarchical multiple regressions used to test the third research hypothesis, namely the capacity of MS patient couple relationship quality (DAS) to predict MS patient and partner depression scores (CES-D), after controlling for MS patient physical functioning and gender. Results are again presented step-by-step to highlight the unique contribution of each variable. Preliminary analyses were performed to ensure no violations of the assumptions of normality, linearity, multicollinearity, and homoscedasticity. MS patient physical functioning and gender were added to the regression model based on the significant correlation coefficients to reduce the error in predicting MS patient depression (Norusis, 1993). MS patient physical functioning and gender were entered at Step 1, explaining 34\% of the variance in MS patient depression scores. After entering patient ratings of couple relationship quality at Step 2, the total variance explained by the model was $46 \%, F(3,50)=$ $13.99, p<.001$. Patient reports of couple relationship quality explained an additional $12 \%$ of the variance in MS patient depression scores, $R^{2} \Delta=.12, F \Delta(1,50)=$ $10.88, p<.01$. In the final model, two of the variables were statistically significant, with MS patient physical functioning recording a higher beta value $(\beta=-.43, p<$ .001) than MS patient reports of couple relationship quality $(\beta=-.36, p<.01)$.

In a comparable hierarchical regression model, MS patient physical functioning and gender were entered at Step 1, explaining $34 \%$ of the variance in MS patient depression scores. After entry of partner couple relationship quality at Step 2, the total variance explained by the model was $35 \%$, $F(3,50)=9.06, p<.001$. Partner couple

Table 2

Multiple Regressions on MS Patient Depression Scores (CES-D)

\begin{tabular}{|c|c|c|}
\hline Variable & $\beta$ & $R^{2}$ \\
\hline MS patient $\mathrm{ADL}$ & $-.51^{* * *}$ & \\
\hline Male gender & $-.24^{*}$ & $R^{2}=.34$ \\
\hline \multicolumn{3}{|l|}{ Adding MS patient DAS } \\
\hline MS patient $\mathrm{ADL}$ & $-.43^{* * *}$ & \\
\hline Male gender & -.17 & \\
\hline MS patient DAS & $-.36^{* *}$ & $R^{2}=.46, R^{2} \Delta=.12$ \\
\hline \multicolumn{3}{|l|}{ Adding MS partner DAS } \\
\hline MS patient $\mathrm{ADL}$ & $-.47^{* * * *}$ & \\
\hline Male gender & -.21 & \\
\hline Partner DAS & -.13 & $R^{2}=.35, R^{2} \Delta=.01$ \\
\hline \multicolumn{3}{|c|}{ Multiple Regressions on Partner Depression Scores (CES-D) } \\
\hline MS patient $\mathrm{ADL}$ & $-.51^{* * * *}$ & \\
\hline Years with partner & $-.51^{* * *}$ & $R^{2}=.33$ \\
\hline \multicolumn{3}{|l|}{ Adding partner DAS } \\
\hline MS patient $\mathrm{ADL}$ & $-.27^{* *}$ & \\
\hline Years with partner & $-.38^{* * * *}$ & \\
\hline Partner DAS & $-.58^{* * *}$ & $R^{2}=.62, R^{2} \Delta=.29$ \\
\hline \multicolumn{3}{|l|}{ Adding MS patient DAS } \\
\hline MS patient ADL & $-.38^{* * *}$ & \\
\hline Years with partner & $-.43^{* * * *}$ & \\
\hline MS patient DAS & $-.42^{* * * *}$ & $R^{2}=.50, R^{2} \Delta=.16$ \\
\hline
\end{tabular}

${ }^{*} p \leq .05 . \quad{ }^{* *} p \leq .01 . \quad{ }^{* * * *} p \leq .001$. 
relationship quality only explained an additional $1 \%$ of the variance in MS patient depression scores, $R^{2} \Delta=.01, F \Delta(1,50)=$ $1.09, p=.30$. In the final model, MS patient physical functioning was the only statistically significant variable $(\beta=-.47$, $p<.001$ ).

Table 2 also shows results from hierarchical multiple regressions used to assess the capacity of partner couple relationship quality (DAS) to predict partner depression scores (CES-D), after controlling for MS patient physical functioning and length of time with current partner. Preliminary analyses were performed to ensure no violations of the assumptions of normality, linearity, multicollinearity, and homoscedasticity. MS patient physical functioning and gender were added to the regression model based on the significant correlation coefficients to reduce the error in predicting MS patient depression (Norusis, 1993). MS patient physical functioning and length of time with current partner were entered at Step 1, explaining 33\% of the variance in partner depression scores. After entering partner ratings of couple relationship quality at Step 2, the total variance explained by the model was $62 \%, F(3,50)=27.30$, $p<.001$. Partner reports of couple relationship quality explained an additional $29 \%$ of the variance in partner depression scores, $R^{2} \Delta=.29, F \Delta(1,50)=38.02, p<$ .001. In the final model, all three variables entered into the model were statistically significant, with partner reports of couple relationship quality recording the highest beta value $(\beta=-.58, p<.001)$, then length of time with current partner $(\beta=$ $-.38, p<.001)$, followed by MS patient physical functioning $(\beta=-.27, p<.01)$.

In a comparable hierarchical regression model, MS patient physical functioning and length of time with current partner were entered at Step 1, explaining 33\% of the variance in partner depression scores. After entering MS patient ratings of couple relationship quality at Step 2, the total variance explained by the model was $50 \%$,
$F(3,50)=16.33, p<.001$. MS patient reports of couple relationship quality explained an additional $16 \%$ of the variance in partner depression scores, $R^{2} \Delta=.16$, $F \Delta(1,50)=16.06, p<.001$. In the final model, all three variables entered into the model were statistically significant, with length of time with current partner recording the highest beta value $(\beta=-.43, p<$ .001 ), then MS patient reports of couple relationship quality $(\beta=-.42, p<.001)$, followed by MS patient physical functioning $(\beta=-.38, p<.01)$. In predicting partner depression, partner reports of couple relationship quality accounted for the largest percentage of variance (29\%), followed by MS patient reports of couple relationship quality (16\%). The relationship between depression and DAS scores was not as strong for MS patients, with patient reports of couple relationship quality accounting for more variance $(12 \%)$ than partner reports (1\%).

Given the female-skewed makeup of the MS patient sample in this study (80\%), the researcher performed secondary analyses to determine if the above results were skewed based on gender effects. In the previous analyses, gender was only used as a control variable in the regression analysis for MS patient depression. Although gender did not significantly correlate to any of the other study variables, independent samples $t$ tests were performed to determine if gender accounted for significant differences in MS patient physical functioning and MS patient and partner reports of couple relationship quality. $T$ tests yielded no significant differences among the study variables based on gender.

\section{DISCUSSION}

The fundamental hypothesis of this study was that couple relationship quality and depression in MS patients and partners would be related to MS patient physical functioning. The results of the present study supported this hypothesis. Results showed direct relationships between cou- 
ple relationship quality and MS patient physical functioning and between depression and MS patient physical functioning.

\section{Association Between Couple Relationship Quality and MS Patient Physical Functioning}

After controlling for MS patient age and length of time in the couple relationship, both MS patient and partner ratings of couple relationship quality were significantly associated with MS patient physical functioning, with partner ratings being the strongest predictor of the two. The association between couple relationship quality and MS patient physical functioning may be explained in several ways. First, the findings that high marital functioning has been shown to improve survival rates after heart failure (Coyne et al., 2001) and kidney disease (Kimmell et al., 2000), enhance physiological functioning (Uchino et al., 1996), and relate to fewer health problems (Wickrama et al., 1997) are supported and expanded upon with this research. Though causal links cannot be made because of the cross-sectional nature of this study, it can be said that couple relationship quality and MS patient physical functioning are related.

Couples who have a high-quality couple relationship may be more available to support each other in difficult circumstances, such as living with MS. This hypothesis is in line with Burman and Margolin's (1992) conclusion that supportive and positive couple relationships have a positive psychological and physical effect during stressful life events. Given that partners of individuals with illness are often looked to as a primary source of support (Coyne \& DeLongis, 1986), they play a key role in providing the kind of support that is related to better physiological functioning (Uchino et al., 1996), improved health outcomes (King, Reis, Porter, \& Norsen, 1993; Kulik \& Mahler, 1989), and fewer symptoms of physical distress in MS patients
(Gulick, 1994; Wethington \& Kessler, 1986).

The findings of the current study expand upon the work by Gold-Spink (2000) that reported a correlational trend approaching significance between ADL-MS scores and partner DAS scores of 18 couples. The present research adds to the current literature by not only confirming and building upon the observed trend between partner reports of couple relationship quality and MS patient physical functioning by finding significance in a more statistically sophisticated regression analysis, but also by showing a significant relationship between MS patient reports of couple relationship quality and MS patient physical functioning.

It is also important to note that more severely physically impaired MS patients and their partners may also have lower couple relationship quality related to the increased burden of care that accompanies greater disability. Again, it is important to remember the direction and causality of the relationship between MS patient functioning and couple relationship quality cannot be identified in cross section research designs such as this, future research is needed to clarify how and under what conditions one variable may predict the other.

\section{Association Between Depression and MS Patient Physical Functioning}

Both MS patient and partner depression scores were significantly associated with MS patient physical functioning, even after controlling for MS patient age and length of time in the couple relationship. The association between depression and MS patient physical functioning found in the present study supports the extant literature showing a link between depression and physiological functioning (Glassman \& Shapiro, 1998; Kiecolt-Glaser \& Newton, 2001; Pennix et al., 1998; Simonsick et al., 1995). Potential explanations for this relationship are offered in the existing litera- 
ture. First, the psychological distress associated with depression decreases physical functioning. Powerful support for this hypothesis comes from the findings of Mohr, Hart, and Vella (2007), which showed psychotherapy aimed at decreasing depression significantly reduced physical disability and fatigue in MS patients. Gulick's (2001) finding that emotional distress significantly predicted activities of daily living functioning and the findings of Osborne, Jensen, Ehde, Hanley, and Kraft (2007) that psychological functioning contributed to the prediction of pain intensity further support this hypothesis.

However, the findings of the current study stand in sharp contrast to the findings of Gottberg et al. (2007) and Moore, MacLeod, Barnes, and Langdon (2006), which found that depressed MS patients and nondepressed MS patients did not differ on physical functioning. In fact, the depression cutoff score variable separating nondepressed patients and partners from depressed patients and partners proved to be the most powerful predictor of MS patient physical functioning in the current research. As previously mentioned, Gottberg et al. (2007) and Moore et al. (2006) both used observed measures of physical functioning in a walking test, whereas the present research used a self-report measure, which may account for disparate findings since self-reports can account for aspects of physical functioning not readily observable.

Partner depression levels may also be explained by the level of burden and responsibility they feel to care for the person with MS. If the MS patient has greater physical disability, the amount of responsibility that partners feel, and the amount of care that MS patients expect from their partners, may increase. McKeown, Porter-Armstrong, and Baxter (2003) found support for this hypothesis in a review that found nine articles reporting an association between providing care for someone with MS and decreased psychological well-being.

\section{Association Between Couple Relationship Quality and Depression}

For MS patients, self-reports of couple relationship quality were significantly associated with MS patient depression scores, even after controlling for MS patient physical functioning and gender. However, partner reports of couple relationship quality were not significantly associated with MS patient depression scores after controlling for MS patient physical functioning and gender. For MS patients, physical functioning was the strongest predictor of MS patient depression.

For partners, self-reports and MS patient reports of couple relationship quality were significantly associated with partner depression scores, even after controlling for length of time in the couple relationship and MS patient physical functioning. Further, MS patient and partner reports of couple relationship quality were the strongest overall predictors of partner depression, even greater than MS patient physical functioning.

The relationship between DAS and depression found in the current research supported the association between high couple relationship quality and lower levels of depression (Weissman, 1987), as well as between low couple relationship quality and depression in couples (Fekete, Stephens, Mickelson, \& Druley, 2006; Heene, Buysse, \& Van Oost, 2007; Weissman, 1987). This finding is particularly meaningful in light of the strong relationship that depression and MS patient physical functioning demonstrated in the present research. Although couple relationship quality did not account for as much variance in ADL-MS as depression scores, DAS scores are significantly related to depression scores.

The social support that a couple is able to offer may account for some of the relationship between DAS and depression scores. This hypothesis is supported by the 
result that a lack of social support is significantly associated with depression in persons with MS (Chwastiak et al., 2002; Gilchrist \& Creed, 1994; Rao et al., 1991). If couples are able to work together through the struggles and challenges of living with MS, both the MS patient and partner may feel less isolated, distressed, and depressed.

To better understand why partner depression scores were significantly related to both partner and patient reports of couple relationship quality, whereas patient depression was related to patient reports of couple relationship quality and not partner, it is important to consider the role of gender in depression. The MS patient sample in the present study was $80 \%$ women. Steck, Amsler, Kappos, and Burgin (2000) found that depression in a woman with MS was associated with depression in her husband, whereas depression in a man with MS was not associated with depression in his wife. These results were explained by the tendency for women to seek multiple sources of social support and men to rely mostly on their female partners. If that concept held true in the present study, it makes sense that the largely female MS patient sample's depression scores would not be tied to their partner's scores since the women likely relied more heavily on other sources for support. Thus, the largely female MS patient depression scores were not related to partner reports of couple relationship quality.

\section{Clinical Implications}

The finding that both couple relationship quality and depression are related to physical functioning, and the additional finding that couple relationship and depression are related, offers compelling evidence for the involvement of partners and/or other close relations throughout the treatment of MS patients. Rather than reinforcing the idea often associated with MS that the illness resides in the patient and is the patient's disease, health professionals must foster a health care culture that gives voice to the systemic impact of MS. Auton (2005) proposed a multifaceted model of care for persons with MS involving a multidisciplinary team to carry out various biopsychosocial treatments. Family and couple-centered preventative biopsychosocial care of MS patients should be developed that involve mental health professionals as part of the health care team working with MS patients and partners from the point of initial diagnosis in neurological health care settings.

One clinical issue raised by Eeltink and Duffy (2004) was the informal agreements that couples living with MS make to avoid uncomfortable subjects such as disability, death, and dying. When couples enter into these often unspoken, informal agreements, they are in effect agreeing to avoid crucial issues that impact the quality of their lives. The results of the current study indicate that partner reports of couple relationship quality accounted for nearly twice as much variance in MS patient physical functioning as compared to MS patient reports of couple relationship quality. This may indicate a discrepancy in the emphasis that each partner places on the couple relationship and the relative influence of MS patient physical functioning for each partner. Such a discrepancy could lead to conflict regarding how much effort and energy is put into the couple relationship and into conversations regarding MS patient physical functioning. Failure to engage in this potentially difficult conflict and conversation deprives couples with MS of the social and emotional support that could be a potential source of increased biopsychosocial well-being (Campbell, 2003; Delongis, Capreol, Holtzman, O'Brien, \& Campbell, 2004; Fekete et al., 2007; Uchino et al., 1996).

As clinicians engage in these conversations and help partners engage with each other, clinicians should remain curious and attuned to the potential influence of gender and power in these conversations. The 
present research suggests that partners of MS patients, which were mostly male in this sample, may be more strongly connected to the quality of the couple relationship than MS patients. Clinicians should be curious as to why this is and assess power and gender dynamics. It is important that partners feel like they also are attended to by professionals because they may feel neglected in some way because of all of the attention that is paid to the MS patient and the illness. However, clinicians should look to see if the male partner's view of the couple relationship has more weight and is attended to more in the couple relationship, while the female partner's views and ideas may be silenced or neglected. Clinicians must open space for dialogue from both partners.

Findings from the present study suggest that depression in both partners can be improved by increasing levels of couple relationship quality. The connection between couple relationship quality and depression is well established (Beach, Fincham, \& Katz, 1998; Finchman \& Beach, 1999). If both partners feel like they have something to look forward to in their couple relationship and anticipate positive future experiences, they are likely to feel less depressed (Moore et al., 2006). In addition to opening up previously unaddressed or difficult conversations, clinicians should help couples to see and focus on anticipated positive future experiences.

McCabe (2006) reported that a positive focus was related to a higher reported quality of life. This is supported by the present findings linking lower levels of depression and higher levels of couple relationship quality to higher levels of MS patient physical functioning. To counteract depression and emphasize a positive focus, a clinician can ask, "With all the difficulty you are experiencing right now, what keeps you going?" or "What do you look forward to?" This focus on the positive can include drawing on the personal strengths and re- silience of each partner, which Blank and Finlayson (2007) reported as a key to coping with MS. Therapists can ask, "What is it about you that makes you capable of rising to such a challenge?" or "What experiences do you draw on to give you the strength you need to face such difficult challenges?" Such questions draw MS patients and partners to the positives and encourage them to discover their strength and resilience amid the many challenges of living with MS. Doing so may help to lower levels of helplessness and increase levels of acceptance, which Evers et al. (2001) found to be associated with positive outcomes in MS patients.

\section{Implications for Future Research}

Future longitudinal research should be designed to measure similar aspects of biopsychosocial functioning, both before and after interventions, designed at improving any area of functioning to measure how changes in one aspect of functioning affects other aspects of functioning. Research that specifically compares couples with low and high relationship quality is needed to better understand the differential impact that low versus high marital quality has on depression and MS patient physical functioning. Past research has shown that lower marital quality has a greater capacity to negatively influence biopsychosocial functioning than high marital quality does to positively influence biopsychosocial functioning (Campbell, 2003; Coyne \& Bolger, 1990). The present research did not employ a large enough sample of both high and low marital quality couples to more rigorously test the differential impact of low and high marital quality. Future research is needed that uses purposeful sampling to recruit a greater number of distressed and nondistressed couples for comparison. A similar argument can be made for research that addresses differences among patients in depression scores. 


\section{Limitations}

Limitations include issues with recruitment and sampling, an inability to determine causal relationships between study variables, and a lack of inclusion of other potentially significant correlates to MS patient physical functioning. Details of these strengths and weaknesses are explained below. The major weakness in the current research is the response rate. The present research reported a one-time response rate of $18 \%$, which requires that two critical issues be considered. First, when the mailing list was obtained through the MS society, the researcher understood that the list consisted only of couples in which one partner had MS. Based on the responses received from persons for whom the study did not apply, either because neither partner had MS or the person with MS did not have a partner (20), it is apparent that the list did not consist solely of couples living with MS. Second, a lower response rate can be attributed to the fact that only responses received from both partners in a couple were included, and it may be more difficult to require both people from a couple to respond than to accept responses from individuals as well as couples.

With the lower response rate, there is likely a sample bias. First, it may be that couples with higher couple relationship quality were more likely to volunteer for the study. In the present sample, the majority of couples were above the couple relationship quality cutoff score indicating distressed couples. This contrasts with the relationship that Burman and Margolin (1992) found between health problems and low couple relationship quality. In addition, the sample may not include a representative number of couples in which the MS patient is experiencing acute exacerbation. These couples may be less likely to fill out the surveys because of the functional limitations that come with MS exacerbations. As a result, the potential response biases make it very difficult to generalize the find- ings to MS couples with more severe marital problems or acute exacerbation.

The study sample was not diverse. Cree et al. (2004) noted that African Americans with MS may experience a more aggressive course of illness. However, only 9 of the 108 participants were people of color. At the same time, the NMSS (2006) reports that African Americans, Asians, and Latinos are diagnosed with MS far less frequently than are White people. In addition, only 11 of the $54 \mathrm{MS}$ patients in the study were male. While this is a substantial skew in gender, this is fairly typical of the MS patient population, wherein women are diagnosed with MS two to three times more often than are men (NMSS, 2006). These biases also limit the generalizability of the findings. In addition, the small number of participants limited the type and sophistication of statistical procedures available for data analysis. Because the size of the current sample is at the low end of the total required for regression analyses, the results of this study should be interpreted cautiously. Clearly future research in the important area of marital process and MS is needed, with larger samples, more sophisticated analyses, and longitudinal data.

Because the present study was crosssectional in nature, the study fails to determine causation. In addition, the present research failed to include other study variables that might have clarified the relationship between variables. For example, the study did not include potentially significant information regarding whether or not the MS patient was currently experiencing an exacerbation of their symptoms and the involvement of the partner in the caregiving process. This is potentially significant information given the link between exacerbation and greater levels of depression (Kroencke et al., 2001). In addition, MS patients currently experiencing an exacerbation may result in a greater need for partner caregiving, which is related to greater distress in caregivers (Baumgar- 
ten, 1989; McKeown et al., 2003). Although a measure of physical functioning may illustrate the exacerbation to some degree, the potential newness and acuteness of the exacerbation was not considered in the present research and should be accounted for in future research. Although this research asked participants to indicate the type of MS and length of time with illness, these variables were not utilized in the analyses. A variable that assesses the degree to which a partner is involved in the caregiving process may also account for some of the variance in the present study variables. Future research will be stronger if these illness-related variables are taken into greater account.

\section{CONCLUSION}

This discussion placed the results of the present study in context of findings from other MS research as well as couples and health research. The present findings demonstrate significant relationships between MS patient and partner depression, couple relationship quality, and MS patient physical functioning that is supported by past research. Clinical implications include the need for clinicians to involve partners of MS patients in treatment, open up taboo topics and meaning-making conversations so both partners feel understood and supported, and look for resilience and positive future events that couples anticipate. The present findings have implications for future research including longitudinal outcome research to apply these findings in a clinical setting, the use of structural equation modeling to clarify the relationships between study variables and determine causation, and research to better understand the differential impact of high and low marital functioning on MS patient physical functioning. Although the present cross-sectional study has sampling and measurement limits, it makes a substantial contribution to the examination of the biopsychosocial functioning of MS patients and partners by filling a gap in the mar- riage and family therapy literature, measuring both MS patients and partners, and moving beyond correlational analyses in the examination of depression, couple relationship quality, and MS patient physical functioning.

\section{REFERENCES}

Arnett, P. A., \& Randolph, J. J. (2006). Longitudinal course of depression symptoms in multiple sclerosis. Journal of Neurological and Neurosurgical Psychiatry, 77, 606-610.

Aronson, K. J. (1997). Quality of life among persons with multiple sclerosis and their caregivers. Neurology, 48, 74-80.

Auton, H. R. (2005). Biopsychosocial treatment of multiple sclerosis. (Unpublished doctoral dissertation). Spalding University, Louisville, $\mathrm{KY}$.

Baumgarten, M. (1989). The health of persons giving care to the demented elderly: A critical review of the literature. Journal of Clinical Epidemiology, 42, 1127-1148.

Beach, S. R. H., Fincham, F. D., \& Katz, J. (1998). Marital therapy in the treatment of depression: Toward a third generation of therapy and research. Clinical Psychology Review, 18, 635-661.

Blank, C. W., \& Finlayson, M. (2007). Exploring the impact of multiple sclerosis on couples: A pilot study. Revue Canadienne D'ergotherapie, $74,134-142$.

Bookwala, J., \& Franks, M. M. (2005). Moderating role of marital quality in older adults' depressed affect: Beyond the main-effects model. The Journal of Gerontology, 60B, 338-341.

Broderick, C. B. (1995). Understanding family process: Basics of family systems theory. New York: Sage.

Burman, B., \& Margolin, G. (1992). Analysis of the association between marital relationships and health problems: An interactional perspective. Psychological Bulletin, $112,39-63$.

Campbell, T. L. (2003). The effectiveness of family interventions for physical disorders. Journal of Marital and Family Therapy, 29, 263281.

Chwastiak, L., Ehde, D. M., Gibbons, L. E., Sullivan, M., Bowen, J. D., \& Kraft, G. H. (2002). Depressive symptoms and severity of illness in multiple sclerosis: Epidemiological study of a large community sample. American Journal of Psychiatry, 159, 1862-1868.

Coyle, C. P., \& Roberge, J. J. (1992). The psychometric properties of the Center for Epis- 
temological Studies-Depression Scale (CES-D) when used with adults with disabilities. Psychology \& Health, 7, 69-81.

Coyne, J. C., \& Bolger, N. (1990). Doing without social support as an explanatory concept. Journal of Social and Clinical Psychology, 9, 148-158.

Coyne, J. C., \& DeLongis, A. (1986). Going beyond social support: The role of social relationships in adaptation. Journal of Consulting and Clinical Psychology, 54, 454-460.

Coyne, J. C., Rohrbaugh, M. J., Shoham, V., Sonnega, J. S., Nicklas, J. M., \& Cranford, J. A. (2001). Prognostic importance of marital quality for survival of congestive heart failure. The American Journal of Cardiology, $88,526-529$.

Crane, D. R., Allgood, S. M., Larson, J. H., \& Griffin, W. (1990). Assessing marital quality with distressed and non-distressed couples: A comparison and equivalency table for three frequently used measures. Journal of Marriage and the Family, 52, 87-93.

Cree, B., Khan, O., Bourdette, D., Goodin, D., Cohen, J., Marrie, R., . . . Hauser, S. (2004). Clinical characteristics of African-Americans vs. Caucasian Americans with multiple sclerosis. Neurology, 63, 2039-2045.

Deal, J. E., \& Anderson, E. R. (1995). Reporting and interpreting results in family research. Journal of Marriage and the Family, 57, 1040-1048.

DeLongis, A., Capreol, M., Holtzman, S., O'Brien, T., \& Campbell, J. (2004). Social support and social strain among husbands and wives: A multilevel analysis. Journal of Family Psychology, 18, 470-479.

Dillman, D. A. (2000). Mail and internet surveys: The tailored design method. New York: Wiley and Sons.

D’Alisa, S., Miscio, G., Baudo, S., Simone, A., Tesio, L., \& Mauro, A. (2006). Depression is the main determinant of quality of life in multiple sclerosis: A classification-regression (CART) study. Disability and Rehabilitation, 28, 307-314.

Eeltink, C., \& Duffy, M. (2004). Restorying the illness experience in multiple sclerosis. The Family Journal: Counseling and Therapy for Couples and Families, 12, 282-286.

Einarsson, U., Gottberg, K., Fredrikson, S., von Koch, L., \& Holmqvist, L. W. (2006). Activities of daily living and social activities in people with multiple sclerosis in Stockholm County. Clinical Rehabilitation, 20, 543551.

Engel, G. L. (1977). The need for a new medical model: A challenge for biomedicine. Science, 196, 129-136.

Engel, G. L. (1980). The clinical application of the biopsychosocial model. The American Journal of Psychiatry, 137, 535-544.

Epstein, N., \& Baucom, D. H. (1988). Outcome research on cognitive-behavioral marital therapy: Conceptual and methodological issues. Journal of Family Psychology, 1, 378384.

Evers, A. W. M., Kraaimaat, F. W., van Lankveld, W., Jongen, P. J. H., Jacobs, J. W. G., \& Bijlsma, J. W. J. (2001). Beyond unfavorable thinking: The illness cognition questionnaire for chronic diseases. Journal of Consulting and Clinical Psychology, 69, 1026-1036.

Fekete, E. M., Stephens, M. A. P., Mickelson, K. D., \& Druley, J. A. (2006). Couples' support provision during illness: The role of perceived emotional responsiveness. Families, Systems, and Health, 25, 204-217.

Finchman, F. D., \& Beach, S. R. (1999). Conflict in marriage: Implications for working with couples. Annual Review of Psychology, 50, 47-77.

Gallo, L. C., Troxel, W. M., Matthews, K. A., \& Kuller, L. H. (2003). Marital status and quality in middle-aged women: Associations with levels and trajectories of cardiovascular risk factors. Health Psychology, 22, 453-463.

Ghaffar, O., \& Feinstein, A. (2007). The neuropsychiatry of multiple sclerosis: A review of recent developments. Current Opinion in Psychiatry, 20, 278-285.

Gilchrist, A. C., \& Creed, F. H. (1994). Depression, cognitive impairment and social stress in multiple sclerosis. Journal of Psychosomatic Research, 38, 193-201.

Glassman, A. H., \& Shapiro, P. A. (1998). Depression and the course of coronary artery disease. American Journal of Psychiatry, 155, 4-11.

Goldman Consensus Group. (2005). The Goldman Consensus statement on depression in multiple sclerosis. Multiple Sclerosis, 11, 328-337.

Gold-Spink, E., Sher, T. G., \& Theodos, V. (2000). Uncertainty in illness and optimism in couples with multiple sclerosis. International Journal of Rehabilitation and Health, 5, 157-164.

Gottberg, K., Einarsson, U., Fredrikson, S., von Koch, L., \& Holmqvist, L. W. (2007). A population-based study of depressive symptoms in multiple sclerosis in Stockholm county: Association with functioning and sense of co- 
herence. Journal of Neurology, Neurosurgery, and Psychiatry, 70, 60-65.

Greene, S. M., \& Griffin, W. A. (1998). Symptom study in context: Effects of marital quality on signs of Parkinson's disease during patientspouse interaction. Psychiatry, 61, 35-45.

Gulick, E. E. (1987). Parsimony and model confirmation of the ADL self-care scale for multiple sclerosis persons. Nursing Research, 36, 278-283.

Gulick, E. E. (1994). Social support among persons with multiple sclerosis. Research in Nursing and Health, 17, 195-206.

Gulick, E. E. (2001). Emotional distress and activities of daily living functioning in persons with multiple sclerosis. Nursing Research, 50, 147-154.

Gulick, E. E. (2003). ADL self-care scale for persons with multiple sclerosis. In O. L. Strickland \& C. DiIorio (Eds.). Measurement of nursing outcomes (Vol. 2): Client outcomes and quality of care (pp. 125-155). New York: Springer.

Heene, E., Buysse, A., \& Van Oost, P. (2007). An interpersonal perspective on depression: The role of marital adjustment, conflict communication, attributions, and attachment within a clinical sample. Family Process, 46, 499-514.

Hollist, C. S., Miller, R. B., Falceto, O. G., \& Fernandes, C. L. C. (2007). Marital satisfaction and depression: A replication of the marital discord model in a Latino sample. Family Process, 46, 485-498.

House, J. S., Landis, K. R., \& Umberson, D. (1988). Social relationships and health. Science, 241, 540-545.

Kiecolt-Glaser, J. K., Fisher, L. D., Ogrocki, P., Stout, J. C., Speicher, C. E., \& Glaser, R. (1987). Marital quality, marital disruption, and immune functioning. Psychosomatic Medicine, 49, 13-34.

Kiecolt-Glaser, J. K., Glaser, R., Cacioppo, J. T., MacCullum, R. C., \& Snydersmith, M. (1997). Marital conflict in older adults: Endocrine and immunological correlates. Psychosomatic Medicine, 59, 339-349.

Kiecolt-Glaser, J. K., Kennedy, S., Malkoff, S., Fisher, L., Speicher, C. E., \& Glaser, R. (1988). Marital discord and immunity in males. Psychosomatic Medicine, 50, 213-229.

Kiecolt-Glaser, J. K., Loving, T. J., Stowell, J. R., Malarkey, W. B., Lemeshow, S., Dickinson, S. L., \& Glaser, R. (2005). Hostile marital interactions, proinflammatory cytokine production, and wound healing. Archives of General Psychiatry, 62, 1377-1384.

Kiecolt-Glaser, J. K., Malarkey, W. B., Chee, M.,
Newton, T., \& Cacioppo, J. T. (1993). Negative behavior during marital conflict is associated with immunological down-regulation. Psychosomatic Medicine, 55, 395-409.

Kiecolt-Glaser, J. K., \& Newton, T. L. (2001). Marriage and health: His and hers. Psychological Bulletin, 147, 472-503.

Kimmel, P. L., Peterson, R. A., Weihs, K. L., Shidler, N., Simmens, S. J., Alleyne, S., ... Phillips, T. M. (2000). Dyadic relationship conflict, gender, and mortality in urban hemodialysis patients. Journal of American Society of Nephrology, 11, 1518-1525.

King, K. B., Reis, H. T., Porter, L. A., \& Norsen, L. H. (1993). Social support and long-term recovery from coronary artery surgery: Effects on patient and spouses. Health Psychology, 12, 56-63.

King, K. E., \& Arnett, P. A. (2005). Predictors of dyadic adjustment in multiple sclerosis. Multiple Sclerosis, 11, 700-707.

Kleiboer, A. M., Kuijer, R. G., Hox, J. J., Jongen, P. J. H., Frequin, S. T. F. M., \& Bensing, J. M. (2007). Daily negative interactions and mood among patients and partners dealing with multiple sclerosis (MS): The moderating effects of emotional support. Social Science and Medicine, 64, 389-400.

Kleiboer, A. M., Kuijer, R. G., Hox, J. J., Schreuurs, K. M. G., \& Bensing, J. M. (2006). Receiving and providing support in couples dealing with multiple sclerosis: A diary study using an equity perspective. Personal Relationships, 13, 485-501.

Kroencke, D. C., Denney, D. R., \& Lynch, S. G. (2001). Depression during exacerbations in multiple sclerosis: The importance of uncertainty. Multiple Sclerosis, 7, 237-242.

Kulik, J. A., \& Mahler, H. I. M. (1989). Social support and recovery from surgery. Health Psychology, 8, 221-238.

Mancini, A. D., \& Bonanno, G. A. (2006). Marital closeness, functional disability, and adjustment in late life. Psychology and Aging, 21, 600-610.

Marcenes, W., \& Sheiham, A. (1996). The relationship between marital quality and oral health status. Psychology and Health, 11, 357-369.

McCabe, M. (2006). A longitudinal study of coping strategies and quality of life among people with multiple sclerosis. Journal of Clinical Psychology in Medical Settings, 13, 369-379.

McKeown, L. P., Porter-Armstrong, A. P., \& Baxter, G. D. (2003). The needs and experiences of caregivers of individuals with mul- 
tiple sclerosis: A systematic review. Clinical Rehabilitation, 17, 234-248.

Mohr, D. C., Hart, S., \& Vella, L. (2007). Reduction in disability in a randomized controlled trial of telephone-administered cognitive behavioral therapy. Health Psychology, 26, 554-563.

Moore, A. C., MacLeod, A. K., Barnes, D., \& Langdon, D. W. (2006). Future-directed thinking and depression in relapsing-remitting multiple sclerosis. British Journal of Health Psychology, 11, 663-675.

Myers, J. K., \& Weissman, M. M. (1980). Use of a Self-Report Symptom Scale to detect depression in a community sample. American Journal of Psychiatry, 137, 1081-1084.

National Multiple Sclerosis Society. (2006). Multiple Sclerosis Information Sourcebook. New York: Information Resource Center and Library of the National Multiple Sclerosis Society.

Norusis, M. J. (1993). SPSS for windows base system user's guide, release 6.0. SPSS, Inc.: Chicago.

Noseworthy, J., Lucchinetti, C., Rodriguez, M., \& Weinshenker, B. (2000). Multiple sclerosis. New England Journal of Medicine, 343, 938952.

O'Leary, K. D., Christian, J. L., \& Mendell, N. R. (1994). A closer look at the link between marital discord and depressive symptomology. Journal of Social and Clinical Psychology, 13, 33-41.

Osborne, T. L., Jensen, M. P., Ehde, D. M., Hanley, M. A., \& Kraft, G. (2007). Psychosocial factors associated with pain intensity, pain-related interference, and psychological functioning in persons with multiple sclerosis and pain. Pain, 127, 52-62.

Penn, P. (2001). Chronic illness: Trauma, language, and writing: Breaking the silence. Family Process, 40, 33-52.

Pennix, B. W. J. H., Guralnik, J. M., Ferrucci, L., Simonsick, E. M., Deeg, D. J. H., \& Wallace, R. B. (1998). Depressive symptoms and physical decline in community-dwelling older persons. Journal of the American Medical Association, 279, 1720-1726.

Prigerson, H. G., Maciejewski, P. K., \& Rosenheck, R. A. (1999). The effects of marital dissolution and marital quality on health and health services use among women. Medical Care, 37, 858-873.

Proulx, C. M., Helms, H. M., \& Buehler, C. (2007). Marital quality and personal wellbeing: A meta-analysis. Journal of Marriage and Family, 69, 576-593.

Radloff, L. S. (1977). The CES-D scale: A self- report depression scale for research in the general population. Applied Psychological Measurement, 1, 385-401.

Randolph, J. J., \& Arnett, P. A. (2005). Depression and fatigue in relapsing-Remitting MS; the role of symptomatic variability. Multiple Sclerosis, 11, 186-190.

Rao, S. M., Leo, G. J., Ellington, L., Nauertz, T., Bernardin, L., \& Unverzagt, F. (1991). Cognitive dysfunction in multiple sclerosis II. Impact on employment and social functioning. Neurology, 41, 692-696.

Roberts, R. E., \& Vernon, S. W. (1983). The Center for Epistemological Studies Depression Scale: It's use in a community sample. Journal of American Psychiatry, 140, 41-46.

Rolland, J. S. (1994). In sickness and in health: The impact of illness of couples' relationships. Journal of Marital and Family Therapy, 20, 327-347.

Ross, C. E., Mirowsky, J., \& Goldsteen, K. (1990). The impact of the family on health: The decade in review. Journal of Marriage and the Family, 52, 1059-1078.

Sandberg, J., \& Harper, J. M. (2000). In search of a marital distress model of depression in older marriages. Aging and Mental Health, 4, $210-222$.

Schmaling, K. B., \& Sher, T. G. (Eds.). (2000). The psychology of couples and illness: Theory, research, and practice. Washington DC: American Psychological Association.

Schwartz, L., \& Kraft, G. H. (1999). The role of spouse responses to disability and family environment in multiple sclerosis. American Journal of Physical Medicine \& Rehabilitation, 78, 525-532.

Simonsick, E. M., Wallace, R. B., Blazer, D. G., \& Berkman, L. F. (1995). Depressive symptomatology and hypertension-associated morbidity and mortality in older adults. Psychosomatic Medicine, 57, 427-435.

Spanier, G. B. (1976). Measuring dyadic adjustment: New scales for assessing the quality of marriage and similar dyads. Journal of Marriage and the Family, 38, 15-28.

Steck, B., Amsler, F., Kappos, L., \& Burgin, D. (2000). Gender-specific differences in coping with chronic somatic disease (e.g. multiple sclerosis). Archives of Women's Mental Health, 3, 15-21.

Thomas, S. P. (1995). Psychosocial correlates of women's health in middle adulthood. Issues in Mental Health Nursing, 16, 285-314.

Uchino, B. N., Cacciopo, J. T., \& Kiecolt-Glaser, J. K. (1996). The relationship between social support and physiological processes: A review with emphasis on underlying mecha- 
nisms and implications for health. Psychological Bulletin, 119, 488-531.

Van der Linden, F. A. H., Kragt, J. J., Hobart, J. C., Klein, M., Thompson, A. J., van der Ploeg, H. M., . . U Uitdehaag, B. M. J. (2006). Proxy measurements in multiple sclerosis: Agreement between patients and their partners on the impact of multiple sclerosis in daily life. The Journal of Neurology, Neurosurgery, and Psychiatry, 77, 1157-1162.

Walker, I. D., \& Gonzalez, E. W. (2007). Review of intervention studies on depression in persons with multiple sclerosis. Issues in Mental Health Nursing, 28, 511-531.

Weinshenker, B. (1994). The natural history of MS. Annals of Neurology, 36, S6-S11.

Weissman, M. M. (1987). Advances in psychiatric epidemiology: Rates and risks for major depression. American Journal of Public Health, 77, 445-451.

Wethington, E., \& Kessler, R. C. (1986). Perceived support, received support, and adjustment to stressful life events. Journal of Health and Social Behavior, 27, 78-89.
Wickrama, K. A. S., Lorenz, F. O., \& Conger, R. D. (1997). Marital quality and physical illness: A latent growth curve analysis. Journal of Marriage and the Family, 59, 143-155.

Wineman, M. N., O'Brien, R. A., Nealon, N. R., \& Kaskel, B. (1993). Congruence in uncertainty between individuals with multiple sclerosis and their spouses. Journal of Neuroscience Nursing, 25, 356-361.

Woollett, S. L., \& Edelmann, R. J. (1988). Marital satisfaction in individuals with multiple sclerosis and their partners; its interactive effect with life satisfaction, social networks, and disability. Sex and Marital Therapy, 3, 191-196.

Yorgason, J. B., Almeida, D., Neupert, S. D., Spiro, A., \& Hoffman, L. (2006). A dyadic examination of daily health symptoms and emotional well-being in late-life couples. Family Relations, 55, 613-624.

Zeldow, P. B., \& Pavlou, M. (1994). Physical disability, life stress and psychological adjustment in multiple sclerosis. Journal of Nervous Mental Disease, 172, 8-84. 